\title{
¿Es compatible el progreso de la razón con el de la poesía? Denis Diderot frente a un dilema del pensamiento ilustrado
}

\author{
Is the progress of reason compatible with the development of \\ poetry? Diderot's stance on an Enlightenment dilemma
}

Nicolás Olszevicki*

\begin{abstract}
Resumen: ¿Es posible que el arte progrese al mismo ritmo que la filosofía racional? $¿$ No existe algún tipo de incompatibilidad constitutiva entre ambos modos de interpretar la realidad, de manera tal que, siempre, la mayor precisión de la última implica una menor intensidad del primero? Tales preguntas constituyeron un vital eje de preocupación para los pensadores de la Ilustración francesa. En este artículo, nos concentramos en la respuesta que Denis Diderot intenta dar al dilema. Mostramos, en primer lugar, cómo el editor de la Encyclopédie diferencia ambas áreas de la producción humana a la hora de trazar su historia: si bien es necesario destacar el progreso de la razón, lo es también el reconocer la decadencia de las artes como una de sus consecuencias. En segundo lugar, mostramos cómo, elaborado este diagnóstico, Diderot procura, a través de propuestas pictóricas, poetológicas y dramatúrgicas, salvar la potencia estética del arte para un siglo ilustrado.
\end{abstract}

Palabras clave: arte, filosofía, Diderot, razón, progreso

Abstract: Can arts and rational philosophy progress at the same time? Isn't there any incompatibility between both ways of approaching reality, the rise of precision of the later implying a fall of intensity of the former? Questions like these had been an important point of concern for some of the most important philosophers of the French Enlightenment. In this paper, we focus on the answers given by Denis Diderot. First, we show that the editor of the Encyclopédie differentiates both areas of human production (art and philosophy) suggesting that the progress of reason brings, as an undesired consequence, the decadence of poetry. Second, we

\footnotetext{
* Se doctoró en Letras en la Universidad de Buenos Aires con una beca del CONICET y es profesor en la carrera de Comunicación en la Universidad Nacional de General Sarmiento. En paralelo a su actividad académica, donde investigó en el campo de la Historia de las Ideas y publicó numerosos artículos en revistas especializadas nacionales e internacionales, desarrolló una larga carrera como comunicador de la ciencia en diversos medios de comunicación. Dirección electrónica: nolsze@gmail.com
} 
reconstruct some of his pictorical, poetological and dramaturgical ideas in order to understand his attemps to save the aesthetic power of arts for an enlightened century.

Keywords: art, philosophy, Diderot, reason, progress

Et si, imprudemment, on lancait devant lui la grande chimère des temps modernes, le ballon-monstre de la perfectibilité et du progrès indéfinis, volontiers il vous demandait : "Où sont donc vos Pbidias ? où sont vos Raphaël? ».

Baudelaire, « L’œuvre et la vie d’Eugéne Delacroix »

\section{Introducción}

La relación existente entre el avance de la razón civilizatoria y el desarrollo tanto de la poesía como del gusto por las artes ha sido un frecuente motivo de reflexión entre los philosophes: baste con invocar, entre tantos otros ejemplos posibles, aquellos pasajes de Le siècle de Louis XIV en los que Voltaire reconoce el ocaso del génie literario durante las Lumières o las provocativas "Réflexions sur l'usage et l'abus de la philosophie dans les matières de goût", leídas por D'Alembert frente a la Académie Française en 1757. No resulta sorprendente que el debate cobre especial protagonismo en la obra de Denis Diderot, uno de los pensadores europeos más preocupados por modernizar el statu quo estético de la época.

Justificadamente, la postura adoptada por este autor con respecto a las nociones de progreso y de civilización en general fue objeto de una importante cantidad de análisis críticos, algunos de los cuales se contradicen entre sí de manera evidente. ${ }^{1}$ Para un lector de fines del siglo XIX como

${ }^{1}$ Pueden consultarse: Faguet, Émile, Dix-buitième siècle: études littéraires, Paris, Société française d'imprimerie et de librairie, 1898 ; Delvaille, Jules, Essai sur l'bistoire de l'idée de progrès jusqu'à la fin du XVIII siècle, Paris, Alcan. 1910; Goggi, Gianluca, "Diderot et le concept de civilisation", Dix-huitième siècle, núm. 29, 1997, pp. 353-373; Ratto, Adrián, "Naturaleza e historia en la obra de Denis Diderot", Revista de Filosofía y Teoría Política, núm. 41, 2010, pp. 129-153 y "El pesimismo histórico en la filosofía de Denis Diderot", Tópicos. Revista de Filosofía de Santa Fe, núm. 22, 2011, pp. 211 231; Ginzo, Arsenio, "Las aporías de la utopía. Progreso y primitivismo en 
Émile Faguet, el philosophe podría ser definido como un primitivista poderosamente influenciado por las tesis rousseaunianas; para otros, como Delvaille, se trataría de un defensor de la idea de un perfeccionamiento gradual de la humanidad.

Pero como han apuntado con acierto Krakeur, en primera instancia y, más recientemente, Ratto, ninguna de las dos lecturas es absolutamente equivocada ni absolutamente cierta: existen, en efecto, pasajes para justificar una u otra caracterización en el heterogéneo corpus diderotiano. Quienes han privilegiado su faceta de autor ilustrado tout court, han tendido indefectiblemente a recurrir a algunos artículos de la Encyclopédie o a un comentario bibliográfico de 1769 sobre la Histoire de Russie de Lomonosov, que poco tiempo antes había sido traducida al francés. Allí, en el contexto de un creciente interés por la "cuestión rusa" en Francia (que, según Adamovsky², funcionó como vía de ingreso del philosophe al debate sobre las conveniencias o inconveniencias de la civilización), aseguraba:

Digan lo que digan Jean-Jacques Rousseau y los fanáticos enemigos del progreso del espíritu humano, es difícil leer la historia de los siglos bárbaros de cualquier pueblo sin alegrarse de haber nacido en un siglo iluminado y en una nación educada. Esos filósofos, apologistas de la ignorancia, deberían explicarse claramente. ¿Nos pretenden brutos, animales estúpidos, sin ninguna regla de costumbres, sin leyes? No osarían decirlo. ¿Le reconocen algún progreso al espíritu humano? En ese caso, que establezcan las cláusulas; que nos marquen el límite de las luces que resulte compatible con nuestra felicidad y que nos indiquen, sobre todo, el modo de frenar [el progreso] y de fijarlo. ${ }^{3}$

Diderot", Anales del seminario de Historia de la Filosofia, núm. 14, 1997, pp. 43-71; Krakeur, Lester, "Diderot and the Idea of Progress", Romantic Review, núm. 29, 1938, pp. 151-159; Lotterie, Florence, Progrès et perfectibilité: un dilemme des Lumières françaises (1755-1814), Oxford, Voltaire Foundation, 2006, entre otros.

2 Adamovsky, Ezequiel, Euro-Orientalism: The Image of Russia in France, c. 1740-1880, Oxford, Peter Lang, 2006.

3 "Quoi qu'en disent Jean-Jacques Rousseau et les fanatiques ennemis des progrès de l'esprit humain, il est difficile de lire l'histoire des siècles barbares de quelque peuple que ce soit, sans se féliciter d'être né dans un siècle éclairé et chez une nation policée. Ces philosophes, apologistes de l'ignorance, devraient bien s'expliquer nettement. Nous veulent-ils brutes, animaux stupides, sans aucune règle de mœurs, 
Quienes, por el contrario, optan por enfatizar su costado primitivista, suelen concentrarse en sus numerosas colaboraciones para la Histoire des deux Indes de Raynal o, más frecuentemente, en el diálogo escenificado en el Supplément au voyage de Bongainville, inspirado por el Voyage autor du monde del navegante francés, en el que la aparente fascinación por el hombre de la naturaleza tahitiano - no exenta sin embargo de matices- va acompañada de una mirada crítica sobre las naciones civilizadas (en particular, en lo concerniente a su dogmatismo cultural, incapaz de comprender la alteridad). La historia de la humanidad es sintetizada allí por uno de los personajes europeos que conversan entre sí como un paulatino alejamiento de la simpleza de lo natural, concebida positivamente, y un reemplazo por lo artificial y lo convencional. A la pregunta de A de si conviene civilizar al hombre o dejarlo librado a sus instintos, B responde:

Si usted se propone ser su tirano, civilícelo. Haga todo lo que esté a su alcance para envenenarlo con una moral contraria a la naturaleza, colóquele trabas de todas las especies, entorpezca sus movimientos con mil obstáculos, adósele fantasmas que lo asusten, eternice la guerra en la caverna y que el hombre natural esté siempre encadenado a los pies del hombre moral. ¿Lo quiere, por el contrario, feliz y libre? No se mezcle en sus asuntos, suficientes incidentes imprevistos lo conducirán a las luces y a la depravación; permanezca usted siempre convencido de que no es por su bien que esos sabios legisladores lo moldearon y lo manipularon para que sea tal como es, sino por el de ellos mismos. $\mathrm{Me}$ refiero a todas las instituciones políticas, civiles y religiosas. Examínelas profundamente: o bien me equivoco fuertemente o usted verá allí a la especie humana sometida de siglo en siglo al yugo que un puñado de diablillos se propuso imponerle. Desconfie de todo aquel que pretende

sans aucunes lois? Ils n'oseraient le dire. Permettent-ils quelques progrès à l'esprit humain? En ce cas, qu'ils fassent donc des clauses; qu'ils nous marquent la limite de lumière compatible avec notre bonheur, et qu'ils nous indiquent surtout le moyen d'enrayer et de s'y fixer ». Para la obra de Diderot, utilizamos la edición preparada por Assézat-Tourneux (A.-T.). En este caso: Diderot, Denis, "Histoire de la Russie. Depuis l'an 862 jusqu'à 1054", A.-T., vol. XVII, pp. 495-496. Todas las traducciones son nuestras. 
poner orden; ordenar es siempre posicionarse como el amo de los otros molestándolos. ${ }^{4}$

Vista a través de este prisma, que valora la libertad y la naturaleza por sobre el orden y la razón, la supuesta barbarie de los pueblos "desordenados" como los calabreses resulta menos viciosa que la urbanité que caracteriza a las metrópolis ilustradas. ${ }^{5}$

Los pasajes citados constituyen apenas una sucinta muestra de las contradicciones que pueden encontrarse en torno al concepto de "progreso" cuando se revisa sin prejuicios la obra del editor de la Encyclopédie. En lugar

${ }^{4}$ «Si vous vous proposez d'en être le tyran, civilisez-le. Empoisonnez-le de votre mieux d'une morale contraire à la nature ; faites-lui des entraves de toute espèce ; embarrassez ses mouvements de mille obstacles ; attachez-lui des fantômes qui l'effrayent ; éternisez la guerre dans la caverne, et que l'homme naturel y soit toujours enchaîné sous les pieds de l'homme moral. Le voulez-vous heureux et libre? Ne vous mêlez pas de ses affaires, assez d'incidents imprévus le conduiront à la lumière et à la dépravation, et demeurez à jamais convaincu que ce n'est pas pour vous, mais pour eux que ces sages législateurs vous ont pétri et maniéré comme vous l'êtes. J'en appelle à toutes les institutions politiques, civiles et religieuses ; examinez-les profondément, et je me trompe fort, ou vous y verrez l'espèce humaine pliée de siècle en siècle au joug qu'une poignée de fripons se promettait de lui imposer. Méfiez-vous de celui qui veut mettre de l'ordre ; ordonner, c'est toujours se rendre le maitre des autres en les gênant» (Diderot, Denis, Supplément au voyage de Bougainville, A.-T., Vol. II, p. 247).

${ }^{5} \mathrm{El}$ anticolonialismo del texto ha sido resaltado y analizado con provecho desde la perspectiva de la teoría poscolonial por Sankar Muthu, Enlightenment against empire, Princeton, Princeton University Press, 2003. Además, una interesante lectura a contrapelo del Supplément fue propuesta recientemente por Sharon Stanley, "Unravelling Natural Utopia. Diderot's Supplement to the Voyage de Bougainville", Political Theory, Vol. 37, núm. 2, 2009, pp. 266-289. Para la autora, el texto diderotiano no exalta, sino que cuestiona la esquemática oposición rousseauniana entre una naturaleza virtuosa y una civilización corrupta. Aunque ofrece una "unyielding critique of civilized Europe" (270), el diálogo rechazaría al mismo tiempo toda forma consolatoria de redención, dado que ni siquiera la naturaleza aparecería representada allí como un lugar de transparencia y bondad. Para Diderot, "there is no consistent, unchanging nature" (282) contra la que puedan medirse los efectos de la civilización, como queda evidenciado en sus Pensées sur l'interpretation de la nature y en Le rêve de D'Alembert. 
de manifestarse monolíticamente a favor de la idea de que la humanidad progresa en su conjunto, o de otorgarle una carga valorativa invariable al proceso de civilisation (concepto, como se sabe, utilizado por primera vez recién en L'ami des hommes de Mirabeau [1757]), el autor de Jacques le fataliste advierte la existencia de diversas áreas de producción humana con distintos modos de funcionamiento y distintas temporalidades, algunas de las cuales considera acechadas ocasionalmente (cuando no dominadas por completo) por el fantasma de la decadencia.

Teniendo en cuenta que ya existen múltiples trabajos que lidian de modo general con el problema de la visión diderotiana sobre el progreso y la civilización, en lo que resta del artículo nos concentraremos en el pensamiento del philosophe sobre la literatura, la dramaturgia y la pintura, y sostendremos que es posible rastrear cierta perseverancia en la idea de que las artes y el genio sufren un proceso de decadencia a medida que las sociedades se refinan. Para el editor de la Encyclopédie, el declive de la poesía coincide casi siempre con el progreso de la filosofía o, al menos, de una forma de la filosofía dominante desde la Antiguëdad, que pretende reducir a razón todas las formas del pensamiento. El reconocimiento del ocaso del poder expresivo del arte a medida que la civilización avanza conduce a Diderot a elaborar, para contrarrestarlo, una poética capaz de apartarse del francés galante y codificado por los y las salonnières y de retrotraerse a las formas más primitivas del lenguaje con el objetivo de recuperar la capacidad de conmover.

\section{Los caminos divergentes de la poesía y la filosofía}

\section{Descolgué de la pared una vieja lira a la que la filosofía le había cortado las cuerdas. ${ }^{6}$ \\ Diderot, Lettres à Falconet, XIII.}

Mucho antes de que los románticos alemanes conviertan dicho diagnóstico en el eje organizador de su programa poetológico, Diderot ya lo advierte con agudeza: el espíritu de la poesía no puede permanecer incólume frente a

${ }^{6}$ "Je décrochais de la muraille une vieille lyre dont la philosophie avait coupé les cordes » (Diderot, Denis, Lettres à Falconet, A.-T., Vol. XVIII, p. 228). 
la progresiva racionalización del mundo, resultado no sólo de las transformaciones epistemológicas derivadas de la Revolución Científica sino, también, del auge del comercio y el cálculo capitalista. Ahora bien, mientras que en los textos más evidentemente políticos el philosophe parece aceptar con resignación que el debilitamiento de las artes y del gusto es uno de los precios a pagar para garantizar el avance de la civilización (en una perspectiva que lo acerca a las ideas de Voltaire), en los escritos específicos sobre literatura, teatro y pintura predomina una mirada melancólica que se lamenta por la excesiva atemperación de las pasiones y procura revivir la potencia estética de las obras del pasado, incluso cuando este proceso implique poner en tela de juicio las premisas del pensamiento filosófico y de la politesse moderna. Roland Mortier ha señalado, al respecto, que Diderot comprendió mejor que todos sus contemporáneos que "la marcha ascendente de las luces" debía pagarse con el alto precio de la "pérdida de una cierta ingenuidad, de la fantasía, de la imaginación y del sueño", necesarias para que el arte alcanzara su máxima expresividad 7 .

Como ejemplo del primero de los casos -esto es, de los escritos políticos-, podemos evocar, entre otros pasajes, uno de sus Fragments politiques. Allí, el editor de la Encyclopédie afirma, con una mirada que rezuma optimismo, que el proceso civilizatorio europeo, uno de cuyos principales motores es la expansión del doux commerce, se ha tornado irreversible. ¿Qué pasará, sin embargo, con las belles lettres y las beaux-arts bajo la calma relativa, la previsibilidad y la perdurabilidad de esas sociedades en las cuales la invención de una máquina, la apertura de una nueva ruta comercial o la construcción de un puerto se convertirán en las "transacciones más importantes"? ¿Podrán continuar produciendo objetos estéticos capaces de "conmover las almas, elevarlas y producir el entusiasmo" («échauffer les âmes, les élever, et produire l'enthousiasme»), cuando es evidente que, a diferencia de la de los guerreros griegos y romanos, la vida de sus miembros es incompatible con los excesos de la épica?8

La pregunta, puede intuirse, tiene una respuesta negativa. Fiel a una teoría mimética de cuño propio $^{9}$-pero, también, fuertemente influenciado

${ }^{7}$ Roland Mortier, Clartés et ombres du Siècle des Lumières, Genève, Droz, 1969, p. 156.
${ }^{8}$ Diderot, Denis, Fragments politiques, A.-T., Vol. IV, p. 43.
9 Puede consultarse, al respecto: Philippe Lacoue-Labarthe, Typography. Mimesis,
Philosophy, Politics, Cambridge, Harvard University Press, 1989, pp. 248-267. El autor 
por A philosophical enquiry into the origin of our ideas of the sublime and of the beautiful (1757), de Edmund Burke-, Diderot considera que los momentos más esplendorosos de la historia de las artes son resultado del reflejo transformado de las acciones sublimes que acontecen en la sociedad, al tiempo que reconoce que estas últimas (entre las cuales se cuenta, por ejemplo, el crimen) ${ }^{10}$ resultan contradictorias con el avance de la civilización. $\mathrm{Si}$, como producto inevitable de la suavización de las costumbres sociales, esas acciones se tornan infrecuentes, desaparece con ellas la fuente de la que beben los historiadores, los oradores y los poetas. Un rápido repaso de la historia de la humanidad puede demostrar que, en efecto,

[f]ue en medio de las tormentas continuas de la [antigua] Grecia que esa comarca se pobló de pintores, de escultores y de poetas. Fue en los tiempos en que esa bestia feroz que se llamaba pueblo romano o bien se devoraba a sí misma, o bien se ocupaba de devorar otras naciones, que los historiadores escribieron y los poetas cantaron. Fue en medio de los problemas civiles en Inglaterra, y luego de las masacres de la Liga y de la Fronda en Francia, que aparecieron los autores inmortales. ${ }^{11}$

ha mostrado, en efecto, que la mímesis diderotiana no es mera reproducción de la naturaleza sino transformación. Denominado por el crítico francés como "mímesis general", la particularidad de este procedimiento, tal como lo elabora el philosophe, es que "no reproduce nada dado" sino que "compensa o suplementa una cierta deficiencia de la naturaleza; su incapacidad para hacerlo todo, para organizarlo todo, hacer de todo su obra, producirlo todo. Es una mímesis productiva que es una imitación de la physis como fuerza productiva o como poiesis. Puede alcanzar, llevar a cabo, terminar la producción natural como tal" (256).

${ }^{10}$ En el Salon de 1765, por ejemplo, advierte: "Je ne hais pas les grands crimes. (...) les grandes et sublimes actions et les grands crimes portent le même caractère d'énergie" (Diderot, Denis, Salon de 1765, A.-T., Vol. X, p. 342).

11 « Ce fut au milieu des orages continus de la Grèce, que cette contrée se peupla de peintres, de sculpteurs et de poëtes. Ce fut dans les temps où cette bête féroce qu'on appelait le peuple romain, ou se dévorait elle-même, ou s'occupait à dévorer les nations, que les historiens écrivirent et que les poëtes chantèrent. Ce fut au milieu des troubles civils en Angleterre, en France après les massacres de la Ligue et de la Fronde, que des auteurs immortels parurent» (Diderot, Denis, Fragments politiques, A.-T., Vol. IV, p. 43). 
La Historia se convierte, de este modo, en un repositorio de verdades incómodas para el optimista cándido: el arte griego emerge como respuesta estética a los contratiempos permanentes del mundo helénico; el romano, a la pulsión belicista y expansionista imperial; el europeo moderno, a la inestabilidad política y a la intolerancia religiosa. A medida que la violencia disminuye, sin embargo, los hombres dejan de reclamar espectáculos que estimulen sus pasiones y encuentran cada vez más satisfacción en la calma y el orden: es entonces que las letras y la pintura, lenta pero constantemente, se aletargan y terminan por apagarse. En este proceso, las sociedades tienden a homogeneizarse y la originalidad deviene prácticamente imposible; no es sorprendente, por tanto, que los grandes genios "se incuben en los tiempos difíciles, eclosionen en los tiempos vecinos de los tiempos difíciles, acompañen el declive de las naciones y se apaguen con ellas". ${ }^{12}$

Dado que el desarrollo del pensamiento racional suele acompañar sincrónicamente al proceso de refinamiento de una nación, no llama la atención que la obstaculización de la evolución de las artes por el avance de la civilización se formule a menudo como una oposición entre dos disciplinas que eran habitualmente concebidas como antagonistas incluso por muchos de los philosophes: la poesía, dominio del gusto, y la filosofía, dominio de la razón. Así, por ejemplo, en el programático artículo "Encyclopédie", Diderot sostiene que la empresa encabezada por él mismo y por $\mathrm{D}^{\prime}$ Alembert es sólo posible en un "siglo filósofo" («siècle philosophe»), capaz de desarrollar la "intrepidez del espíritu” («hardiesse d'esprit») de manera mucho más consecuente que "en los siglos pusilánimes del gusto" («dans les siècles pussilanimes du goût»). La idea se repite, previsiblemente, toda vez que Diderot trata de pensar el desarrollo de las naciones desde la perspectiva de la filosofía política. Así ocurre, nuevamente, en el Plan d'une université pour le gouvernement de Russie, escrito en 1775 por encargo de la emperatriz Catalina II. El autor comienza por realizar un elogio general de la instrucción como herramienta para alejar a los pueblos de su "estado primitivo de barbarie" («état primitif de barbarie»). Propia de esclavos y de salvajes, la ignorancia puede y debe ser combatida mediante la educación, capaz de suavizar los caracteres, sublimar los vicios,

\footnotetext{
12 «Se couvent dans les temps difficiles; ils éclosent dans les temps voisins des temps difficiles; ils suivent le déclin des nations, ils s'éteignent avec elles » (Ibid, p. 44).
} 
inspirar el amor del orden y de la virtud: con este objetivo en mente, la formación debe apuntar a generar "más filósofos que médicos, más médicos que hombres de leyes, más hombres de leyes que oradores, casi nulos poetas" («plus de philosophes que de médecins, plus de médecins que d’hommes de loi, plus d'hommes de loi que d'orateurs, presque point de poëtes») ${ }^{13}$.

La perspectiva, como ya hemos adelantado, es diferente cuando se revisan los escritos propiamente estéticos, o que tienen al arte por objeto principal de reflexión: en ellos, la excelencia artística perdida por culpa del avance civilizatorio y de los excesos de la filosofía es objeto de una evocación nostálgica que, lejos de aceptarla con pasividad, pretende recuperarla para la edad moderna. En un célebre pasaje de su Discours sur la poésie dramatique, por caso, Diderot advierte:

Cuanto más civilizado y amable es un pueblo, menos poéticas son sus constumbres. (...) La poesía necesita cierta dosis de lo enorme, de lo bárbaro, de lo salvaje. ¿Cuándo se verá nacer a los poetas? Será luego de los tiempos de desastres y de grandes infelicidades; cuando los pueblos arrasados comiencen a respirar nuevamente. ${ }^{14}$

La evolución del genio artístico sigue un camino independiente del cuando no opuesto al- recorrido de la filosofía racional. En efecto, en la Promenade Vernet de 1767, el autor contrapone explícitamente ambas lógicas:

Me parece que la lógica de la razón ha realizado progresos bien diferentes a los de la lógica del gusto. Esta última es tan fina, tan sutil, tan delicada, supone un conocimiento tan profundo del espíritu y del corazón humano, de sus pasiones, de sus prejuicios, de sus errores, de sus gustos, de sus terrores, que pocos están en condiciones de entenderla, y menos aún de encontrarla. Es mucho más sencillo señalar el vicio de un razonamiento que la razón de una belleza. Por otra parte,

${ }^{13}$ Diderot, Denis, «Plan d'une université pour le gouvernement de Russie », A.-T., Vol. III, p. 444.

14 «Plus un peuple est civilisé, poli, moins ses moeurs sont poétiques (...). La poésie veut quelque chose d'énorme, de barbare et de sauvage (...). Quand vera-t-on naitre des poètes ? Ce sera après le temps de désastres et de grands malheurs; lorsque les peuples harassés commenceront à respirer» (Diderot, Denis, "Discours sur la poésie dramatique », A.-T., Vol. VII, p.370). 
una es mucho más antigua que la otra. La razón se ocupa de las cosas; el gusto, de su manera de ser. A este último hay que tenerlo, ése es el punto fundamental, pero tenerlo de una cierta manera (...). La naturaleza reclama lo necesario, de lo cual es penoso estar privado. El gusto lo reclama con cualidades accesorias que lo tornen agradable. ${ }^{15}$

En ese mismo diálogo ficticio, el autor reconoce la mayor potencia expresiva de los pueblos bárbaros por sobre los civilizados y advierte, nuevamente, que el esprit philosophique resulta contradictorio con la poesía, en tanto reclama "comparaciones más estrechas, más estrictas, más rigurosas" («comparaisons plus reserrées, plus strictes, plus rigoureuses»): su marcha reglada, organizada, dogmática, se muestra enemiga de los ensayos y los tanteos característicos de la imaginación poética, gracias a los cuales el artista es capaz de encontrar imágenes que, si no más exactas, cuentan sin embargo con un mayor poder evocatorio en los lectores.

Siguiendo esta lógica, el modelo ideal de la belleza, que había funcionado como paradigma y guía de la creación para los defensores de la estética clásica y de la mímesis de los autores antiguos resulta, en el mejor de los casos, estéril para la composición artística, como indica ya desde la carta inicial dirigida a Melchior Grimm:

Modelo ideal de la belleza, línea verdadera no tradicional, que se disipa casi junto con el hombre de genio que forma durante un tiempo el espíritu, el carácter, el gusto por las obras de un pueblo, de un siglo, de

15 «Il me semble que la logique de la raison a fait bien d'autres progrès que la logique du goût. Aussi celle-ci est-elle si fine, si subtile, si délicate, suppose une connaissance si profonde de l'esprit et du cœur humain, de ses passions, de ses préjugés, de ses erreurs, de ses goûts, de ses terreurs, que peu sont en état de l'entendre, bien moins encore en état de la trouver. Il est bien plus aisé de démêler le vice d'un raisonnement, que la raison d'une beauté. D'ailleurs, l'une est bien plus vieille que l'autre. La raison s'occupe des choses; le goût, de leur manière d'être. Il faut avoir, c'est le point important ; puis il faut avoir d'une certaine manière ; d'abord une caverne, un asile, un toit, une chaumière, une maison ; ensuite une certaine maison, un certain domicile ; d'abord une femme, ensuite une certaine femme. La nature demande la chose nécessaire. Il est fâcheux d'en être privé. Le goût la demande avec des qualités accessoires qui la rendent agréable » (Diderot, Denis, Salon de 1767, A.-T., Vol. XI, p.130). 
una escuela; modelo ideal de la belleza, línea verdadera sobre la cual el hombre de genio tendrá una noción más o menos rigurosa de acuerdo al clima, al gobierno, a las leyes, a las circunstancias que lo vieron nacer; modelo ideal de la belleza, línea verdadera, que se corrompe, que se pierde y que no será reencontrada de manera perfecta en un pueblo sino mediante el retorno al estado de barbarie, puesto que es la única condición en la que los hombres, convencidos de su ignorancia, pueden decidirse a la lentitud del tanteo; los otros permanecen mediocres, precisamente porque nacen, por decirlo de alguna manera, sabios..$^{16}$

En este proceso de deconstrucción y reformulación de la noción clásica, el "modelo ideal de belleza", producto del genio, termina caracterizado, paradójicamente, como un original que no reconoce antecedentes y que no produce (que no puede producir) más que copias deficientes. Luego de su irrupción imprevista, del momento sorpresivo del éxtasis, las sucesivas imitaciones son el testimonio inapelable de la continua decadencia que, necesariamente, lo sucede, y que sólo parece pasible de revertirse con un retorno al estado de barbarie.

Alejado del carácter irracional, de ese enthousiasme que gobierna la actividad genial, el philosophe (el savant) aparece representado como un cómplice involuntario del ocaso de la poesía, a la que se considera incapaz de lograr en la contemporaneidad los efectos que producía entre su público la literatura grecolatina:

Se introduce mediante la razón una exactitud, una precisión, un método, una suerte de (perdonadme la palabra) pedantería que mata todo. Todos los prejuicios civiles y religiosos se disipan, y es increíble cómo la incredulidad le quita recursos a la poesía. Las costumbres se refinan, los

\footnotetext{
16 « Modèle idéal de la beauté, ligne vraie non traditionnelle, qui s'évanouit presque avec l'homme de génie qui forme pendant un temps l'esprit, le caractère, le goût des ouvrages d'un peuple, d'un siècle, d'une école; modèle idéal de la beauté, ligne vraie, dont l'homme de génie aura la notion plus ou moins rigoureuse, selon le climat, le gouvernement, les lois, les circonstances qui l'auront vu naître ; modèle idéal de la beauté, ligne vraie, qui se corrompt, qui se perd et qui ne se retrouverait peut-être parfaitement chez un peuple, que par le retour à l'état de barbarie; car c'est la seule condition où les hommes, convaincus de leur ignorance, puissent se résoudre à la lenteur du tâtonnement; les autres restent médiocres, précisément parce qu'ils naissent, pour ainsi dire, savants » (Ibid., p. 14. Las cursivas son nuestras).
} 
usos bárbaros, poéticos y pintorescos se suspenden y es increíble el mal que ese monótono refinamiento le provoca a la poesía. ${ }^{17}$

La politesse, ese refinamiento artificial y artificioso que Jean-Jacques Rousseau había diagnosticado como el más importante mal du siècle, daña irreversiblemente la capacidad expresiva de las Bellas Artes. Si uno de los rasgos principales del proceso de civilización es justamente el perfeccionamiento moral de las sociedades, la crítica diderotiana apunta, por momentos implícita y por momentos explícitamente, contra ese núcleo de identidad del pensamiento ilustrado (del que, malgré soi, él mismo es una de sus caras más visibles): el progreso de las artes es concebido como parcialmente independiente del progreso moral, en tanto y en cuanto este último implica, necesariamente, una pérdida de energía, parámetro ineludible para medir la calidad de una obra de arte según el sistema del gusto diderotiano. ${ }^{18}$ Esta idea, que aparece matizada en algunos de sus escritos más analizados por la crítica $^{19}$-en los cuales, según ha sugerido Michel Delon, ${ }^{20}$ de lo que se trata es de aprovechar esa «beauté du crime» para lograr una obra moralmente relevante, del mismo modo que la tragedia genera el efecto catártico exhibiendo el sufrimiento de sus protagonistas-, es

17 «Il s'introduit par la raison une exactitude, une précision, une méthode, pardonnez-moi le mot, une sorte de pédanterie qui tue tout. Tous les préjugés civils et religieux se dissipent; et il est incroyable combien l'incrédulité ôte de ressources à la poésie. Les mœurs se policent, les usages barbares, poétiques et pittoresques cessent et il est incroyable le mal que cette monotone politesse fait à la poésie » (Ibid., p. 131).

18 "Aunque Diderot habla de la belleza, su insistencia en la 'energía', uno de los temas más importantes en las definiciones retóricas de lo sublime, funciona no solamente para equiparar acciones beneficiosas y criminales sino para atar esas acciones a la estética, tornándolas productivas para el arte". La cita es de Steintrager, James, Cruel Delight: Enlightenment Culture and the Inhuman, Bloomington, Indiana University Press, 2004, p. 149. Nos hemos ocupado de la importancia de la energía para el concepto diderotiano de lo sublime en Olszevicki, Nicolás, «L'ekphrasis dans la théorie dramatique de Diderot», Recherches sur Diderot et sur l'Encyclopédie, 2016/1 (núm. 51), pp. 63-73.

${ }^{19}$ Como los ensayos sobre el teatro o los Salones.

${ }^{20}$ Delon, Michel, « La beauté du crime », Europe, núm. 661, 1984, pp. 73-83. 
enunciada con mayor radicalidad en algunas de sus cartas. Así, por ejemplo, en una misiva dirigida a su amante Sophie Volland, afirma:

Si los malvados no tuvieran esa energía en el crimen, los buenos no tendrían la misma energía en la virtud. Si el hombre debilitado no puede conducirse hacia los grandes males, tampoco podrá conducirse hacia los grandes bienes; buscando mejorarlo de un lado, lo estaría degradando del otro. Si Tarquino no osa violar a Lucrecia, Mucio Escévola no pondría su puño sobre un brasero ardiente. ${ }^{21}$

La energía de la virtud -lo que podríamos llamar el "sublime moral" - sólo puede aparecer como contraste, o, mejor dicho, como consecuencia irremediable, de la energía del vicio. La poderosa imagen de Mucio Escévola colocando su mano sobre un brasero ardiente para expiar sus culpas por haber matado al hombre equivocado, condensación instantánea de la virtud con una innegable potencialidad pictórica -como testimonian los múltiples cuadros dedicados al episodio desde el Renacimiento-, se presenta como un desprendimiento natural del vicio que determinó la caída de los Tarquinos y el surgimiento de la República romana.

En otra epístola, el 18 de julio de 1762, la postura es incluso más radical: la teleología moral, que parecía justificar la representación del mal como medio de purgar y formar a los hombres, se desvanece en beneficio de la autonomía radical de la energía poética. En una discusión sobre el personaje de Pamela, protagonista de la exitosísima novela homónima de Richardson, Diderot indica provocativamente: "Casi siempre aquello que perjudica la belleza moral redobla la belleza poética. No se producen sino cuadros tranquilos y fríos mediante la virtud; son la pasión y el vicio los que animan las composiciones del pintor, del poeta, del músico"22.

\footnotetext{
21 «Si les méchants n’avaient pas cette énergie dans le crime, les bons n'auraient pas la même énergie dans la vertu. Si l'homme affaibli ne peut plus se porter aux grands maux, il ne pourra plus se porter aux grands biens ; en cherchant à l'amender d'un côté, vous le dégradez de l'autre. Si Tarquin n'ose violer Lucrèce, Scévola ne tiendra pas son poignet sur un brasier ardent » (Diderot, Denis, Lettres à Sophie Volland, A.T., Vol. XVIII, p. 469).

22 « C'est presque toujours ce qui nuit à la beauté morale qui redouble la beauté poétique. On ne fait guère que des tableaux tranquilles et froids avec la vertu ; c'est
} 
En sus manifestaciones más extremas -que no sólo allanan el terreno para las formulaciones sadianas de fin-de-siècle, sino que, de paso, anticipan algunos puntos de la doctrina de la autonomía radical del arte que tomará forma definitivamente en el seno de la Ilustración y del Romanticismo alemanes-23, el reconocimiento de la independencia de la literatura, la pintura y la música con respecto al avance de la civilización implica al mismo tiempo un reconocimiento de su libertad con respecto a las restricciones que pudieran imponérsele desde el ámbito de la moral. De ahí que, nuevamente en el Salon de 1767, Diderot afirme provocativamente que existe "una moral propia a los artistas, o al arte" («une morale propre aux artistes, ou à l'art») y reconozca que "esa moral podría ir a contracorriente de la moral usual" («cette morale pourrait bien être au rebours de la morale usuelle») ${ }^{24}$.

\section{La pérdida del carácter poético del lenguaje originario}

\subsection{La herencia clásica en el pensamiento ilustrado}

Esta idea de que la poesía y el genio declinan como consecuencia del avance de la civilización y de la filosofía, que aparece en muy diversos autores a lo largo del siglo XVIII, es objeto de especial atención y elaboración teórica en el marco de las importantes especulaciones ilustradas sobre el origen y la evolución del lenguaje humano, desde la Scienza Nuova de Vico (1725) hasta la Abhandlung über den Ursprung der Sprache de $\operatorname{Herder}^{25}$ (1772). Si es cierto que la Ilustración, a nivel pan-europeo, hizo del vínculo entre lenguaje y civilización un verdadero topos, los gérmenes de la reflexión filosófica en torno a esta problemática pueden encontrarse ya en la cultura griega clásica,

la passion et le vice qui animent les compositions du peintre, du poète, du musicien ».

${ }^{23}$ Sobre este punto, puede consultarse con provecho el texto de Burello, Marcelo, Autonomia del arte y autonomía estética. Una genealogía, Buenos Aires, Miño y Dávila, 2015.

${ }^{24}$ Diderot, Denis, Salon de 1767, A-T, vol. XI, p. 124.

${ }^{25}$ Para una breve historia de esas discusiones sobre el lenguaje en el siglo XVIII, puede consultarse el compacto y provechoso trabajo de Aarsleff, Hans, "Philosophy of language", en Haakonsen, Knut (coord.), Cambridge History of Eighteenth Century Philosophy, Cambridge, Cambridge UP, 2006, pp. 451-496. 
en la cual, como es bien sabido, el conocimiento profundo de la lengua funcionaba, a la vez, como paradigma identitario y como justificación del rechazo de la alteridad. Recuérdese, en este punto, que el concepto de "barbarie", principal opuesto al de "civilización" desde el siglo XVIII hasta

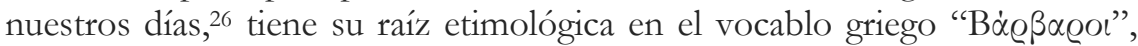
que definía en principio a aquellos incapaces de dominar fluidamente la lengua griega (esto es, a todos los no-griegos) y que Homero había utilizado como atributo para describir el habla de los carios. ${ }^{27}$

Como ha mostrado en un precioso estudio Deborah Levine Gera, ${ }^{28}$ diversos filósofos y literatos griegos consideraron que, de hecho, el nivel de elaboración y de complejidad de una lengua era un indicador fiel de su grado de civilización. En Ilíada, por ejemplo, la carencia de un dialecto unificado entre los troyanos aparecía como posible explicación de su débil sociabilidad y de su falta de organización, en contraste con las del ejército aqueo. En un caso más imaginativo y extremo, los cíclopes, cuya imagen servía para ilustrar los comienzos balbuceantes de la sociedad humana, eran representados como poseedores de una lengua primitiva, tosca, incapaz de percibir los matices y los juegos de sentido característicos de los lenguajes más avanzados. La célebre burla de Ulises a Polifemo, tal vez el momento de Odisea donde más prístinamente queda evidenciada su incomparable metis, no es otra cosa que el aprovechamiento de la dificultad del cíclope para dominar el retruécano y es, en este sentido, un triunfo simbólico de la civilización por sobre la barbarie.

Esta perspectiva, que relaciona el desarrollo y complejización de una lengua con el avance de la civilización, fue retomada y reelaborada por múltiples autores durante la era ilustrada. En su Fable of the bees, por ejemplo, Bernard de Mandeville considera a la génesis y evolución de la retórica como el paso fundamental para la puesta en marcha del proceso civilizatorio y como un vehículo indispensable para la socialización. Luego de un primer momento en que el lenguaje gestual resultaba suficiente para transmitir las

\footnotetext{
${ }^{26}$ La evolución del concepto hasta el presente ha sido estudiada en un importante libro reciente: Boletsi, Maria, Barbarism and its discontents, California, Stanford University Press, 2016.

${ }^{27}$ Cfr. Hartog, François, Memoria de Ulises, Buenos Aires, FCE, 1999, pp. 11-147.

28 Levine Gera, Deborah, Ancient greek ideas on speech, language and civilization, Oxford, Oxford UP, 2003.
} 
emociones de manera inmediata de un sujeto a otro, el lenguaje verbal convencional emerge apenas se torna necesario evocar objetos que no están inmediatamente presentes frente a los sentidos de los participantes del diálogo y se perfecciona por vías de la razón y la reflexión: es este nuevo lenguaje pulido el que permitirá el desarrollo de la retórica, la proliferación de oradores encargados de fijar las leyes («Lawgivers») que persuaden mediante la palabra de la conveniencia de moderar los apetitos naturales y, como corolario, la organización política de las comunidades salvajes en base a una moral artificial. El pasaje del estado de naturaleza a la sociedad moderna, mediado por el refinamiento del lenguaje, implica necesariamente una pérdida: la de la inmediatez expresiva del gesto, de las "naturally expressive forms of sympathy to the other", como las ha llamado en un iluminador artículo E. J. Hundert. ${ }^{29} \mathrm{El}$ lenguaje articulado se presenta, desde entonces, como el medio a través del cual "arose the deceptions required for the pleasures of civilization, maintained on the ruins of transparent gestural understanding".

La tradición de reflexión lingüística sobre la que Mandeville construye sus provocativas especulaciones se remonta a una fuente antigua que los autores ilustrados, especialmente los materialistas pero no sólo ellos, revisitarán una y otra vez a lo largo de los siguientes setenta años: el De rerum natura de Lucrecio. ${ }^{30}$ No es posible realizar aquí un análisis pormenorizado de esa obra; baste con señalar que, en el libro $\mathrm{V}$, uno de los elementos fundamentales de la breve reflexión lucreciana sobre el surgimiento del lenguaje, considerado también un momento fundacional del proceso de civilización, es su carácter originariamente emotivo: del mismo modo que los animales se valen de sonidos para expresar dolor, miedo o felicidad, el hombre los utiliza con el fin de transmitir sus sensaciones primarias. ${ }^{31}$

29 Hundert, Edward J., "The Thread of Language and the Web of Dominion: Mandeville to Rousseau and Back", Eighteenth-Century Studies, Vol. 21, núm. 2, 1987, pp. 169-191.

30 Sobre la incidencia de Lucrecio en la Ilustración europea, puede consultarse el texto de Baker, Eric, "Lucretius in the European Enlightenment", en Gillespie, Stuart, The Cambridge Companion to Lucretius, Cambridge, Cambridge University Press, pp. 274-288.

31 Cfr. Levine Gera, op.cit., p. 39. 
La idea de que en un principio la lengua no tenía una función nominativa sino expresiva y que comportaba, en consecuencia, un carácter inherentemente poético - en tanto y en cuando se entienda, como reconocen ya diversos pensadores de la época ilustrada, que la función de la poesía es, esencialmente, transmitir sentimientos-, aparece desarrollada con claridad en la Scienza Nuova de Vico. Allí, en una larga argumentación contra el racionalismo cartesiano, el napolitano divide la historia del lenguaje en tres etapas (edad de los dioses, de los héroes y de los humanos): mientras en la primera los gestos alcanzaban como medio de comunicación, en la segunda aparecía el lenguaje articulado y finalmente, se desarrollaba el lenguaje racional y por convención. Para el napolitano, la poesía era cronológicamente anterior a la prosa y el lenguaje de los primeros tiempos poseía mayor riqueza en contenido emocional, al punto que incluso sus conocimientos astronómicos, geográficos, morales, políticos y sociales, a priori más adecuados para el ejercicio racional, podían describirse como poéticos.

Tal perspectiva no es, como puede sospecharse, ajena al ámbito francés. En las Réflexions critiques sur la poésie et la peinture, por ejemplo, Du Bos distingue los modos de afección de las impresiones generadas por la palabra de aquellos generados por la imagen, en un capítulo en el que se propone desentrañar si resulta más fuerte la influencia sobre los hombres de la pintura o la de la poesía. La opción dubosiana por la pintura aparece justificada en virtud del carácter inmediato de la recepción visual, en contraste con la lenta formación de la imagen a través de signos convencionales. A diferencia de la palabra escrita, que demanda, tanto para su intelección como para su disfrute, un largo proceso educativo al que no todos pueden acceder, la pintura se vale de signos naturales, gracias a los cuales es capaz de afectar más profundamente el corazón humano:

Los versos más conmovedores no sabrán emocionarnos sino por grados y accionando unos después de otros diversos resortes de nuestra máquina. Las palabras deben en primer lugar despertar las ideas de las cuales no son más que signos arbitrarios. Luego, es preciso que esas ideas 
se acomoden en la imaginación y que formen allí esos cuadros que nos conmueven y esas pinturas que nos interesan. ${ }^{32}$

Aunque con matices, esta idea de que el lenguaje articulado, por su naturaleza dilatoria, puede resultar un obstáculo a la hora de expresar y transmitir emociones es defendida también por Batteux y Condillac, en un contexto en el que la preocupación por los perniciosos efectos del abus des mots, heredada de las advertencias epistemológicas de Bacon y de Locke, ${ }^{33}$ permea el escenario intelectual francés. En Les beaux arts reduits a un même principe, por caso, Batteux distingue tres medios para expresar las ideas y los sentimientos: la palabra, el tono de voz y el gesto. Si bien la palabra es aquel al que los hombres suelen prestarle mayor atención, puesto que permite una mayor precisión conceptual, tanto el tono como "los movimientos exteriores y las actitudes del cuerpo" («les mouvements extérieurs et les attitudes du corps») poseen sobre ella notables ventajas: al ser naturales, presuponen un intérprete universal capaz de comprenderlas en cualquier lugar del globo, incluso entre los pueblos más bárbaros. Al mismo tiempo, parecen diseñados especialmente para expresar con fidelidad los sentimientos: "La palabra nos instruye, nos convence, es el órgano de la razón; pero el tono y el gesto son los del corazón: nos conmueven, nos invaden, nos persuaden. La palabra no expresa la pasión sino por medio de ideas a las cuales los sentimientos están ligados, y como por reflexión". ${ }^{34}$

\footnotetext{
32 «Les vers les plus touchants ne sauroient nous émouvoir que par dégrès et en faisant jouer plusieurs ressorts de notre machine les uns après les autres. Les mots doivent d'abord réveiller les idées dont ils ne font que des signes arbitraires. Il faut ensuite que ces idées s'arrangent dans l'imagination \& qu'elles y forment ces tableaux qui nous touchent et ces peintures qui nous interessent » (Du Bos, JeanBaptiste, Réflexions critiques sur la poésie et la peinture, Paris, Pissot, 1755, p. 377).

33 Ricken, Ulrich, "Réflexions du XVIIIe siècle sur l'abus des mots », Mots, núm. 4, 1982, pp. 29-45 ; Rosenfeld, S., A Revolution in Language. The Problem of Signs in Late Eighteenth-Century France, Stanford, Stanford University Press, 2001, pp. 17-20.

34 « La parole nous instruit, nous convainc, c'est l'organe de la raison; mais le ton et le geste sont ceux du cœur : ils nous émeuvent, nous gagnent, nous persuadent. La parole n'exprime la passion que par le moyen des idées auxquelles les sentiments sont liés, et comme par réflexion » (Batteux, Charles, Les Beaux-Arts réduits à un même principe, Paris, Durand, 1746, p. 254).
} 
Herramientas privilegiadas del «dictionnaire de la simple nature», el tono y el gesto impactan directamente, sin demoras innecesarias, en el corazón de los receptores y constituyen, por tanto, un acervo invaluable, aunque habitualmente despreciado, para el artista:

Contienen una lengua que todos conocemos desde el nacimiento, y de la que nos servimos para anunciar todo lo que tiene relación con las necesidades y la conservación de nuestro ser: ella es potente, concisa, enérgica. ¡Qué mejor repositorio para el arte, cuyo objeto es remover el alma, que un lenguaje cuyas expresiones son más bien aquellas de la propia humanidad, de todos los hombres $!^{35}$

Condillac, por su parte, especula en su célebre Essai sur l'origine des connaisances humaines con que, en los comienzos de la humanidad, la poesía emergió como una derivación natural del "lenguaje de acción” («langage d'action»), entendido como una combinación de gestualidad y gritos naturales: en esos tiempos, la prosodia se acercó al canto y el estilo y, con el fin de evocar "las imágenes sensibles del lenguaje de acción” («les images sensibles du langage d'action»), incorporó "toda suerte de figuras y de metáforas" («toutes sortes de figures et de métaphores»), convirtiéndose en "una verdadera pintura" («une vrai peinture»). De acuerdo con la concepción condillaceana:

El estilo, en su origen, fue poético, puesto que comenzó por pintar las ideas con las imágenes más sensibles, y era, por otra parte, extremadamente mesurado. Pero a medida que las lenguas devinieron más y más abundantes, el lenguaje de acción se abolió poco a poco; la vOZ varió menos, el gusto por las figuras y las metáforas (...) disminuyó sensiblemente y el estilo se aproximó al de nuestra prosa. ${ }^{36}$

\footnotetext{
35 « Ils contiennent une langue que nous savons tous en naissant, et dont nous nous servons pour annoncer tout ce qui a rapport aux besoins et à la conservation de notre être : aussi est-elle vive, courte, énergique. Quel fond pour les arts dont l'objet est de remuer l'âme, qu'un langage dont toutes les expressions sont plutôt celles de l'humanité même, que celles des hommes!» (Ibid., p. 255).

36 « Le style, dans son origine, a été poëtique ; puisqu'il a commencé par peindre les idées avec les images les plus sensibles, qu'il étoit d'ailleurs extrêmement mesuré.
} 
La omnipresente distinción, elaborada por los lógicos de Port-Royal, entre los signos naturales y los signos de institución, y la asociación de los primeros con las pasiones y con el arte y de los segundos con la razón y la filosofía, ordena también el extraño Essai sur l'origine des langues de Rousseau, publicado póstumamente, en el que el autor discute tanto con la teoría musical de Jean-Philippe Rameau como con las especulaciones lingüísticas de Condillac. ${ }^{37}$ Según el citoyen de Genève, el lenguaje surge entre los humanos primitivos por la necesidad de comunicar sus sentimientos y sus pensamientos; si bien tanto la voz como el gesto son naturales (en el sentido de que ambos son el producto de la evolución natural de los hombres, y no de un acto de donación divino), este último es más elocuente que la primera: "Aquello que los antiguos decían más vivamente, no lo expresaban mediante palabras sino mediante signos; no lo decían: lo mostraban” (« Ce que les anciens disaient le plus vivement, ils ne l'exprimaient pas par des mots mais par des signes; ils ne le disaient pas, ils le montraient »). Paradójicamente, el lenguaje más enérgico, desde el punto de vista de la retórica, es el que precede al habla y prescinde de ella; lo que llama "elocuencia muda"

Mais, les langues devenant plus abondantes, le langage d'action s'abolit peu à peu ; la voix se varia moins; le goût pour les figures \& les métaphores (...) diminua insensiblement, \& le style se rapprocha de notre prose » (Condillac, Étienne Bonnot de, Essai sur l'origine des connaissances humaines, Paris, Mortier, 1746, p. 104).

${ }^{37}$ El especialista argentino Emilio Bernini ha realizado una excelente introducción a los principales problemas del Essai en su traducción para la Editorial Colihue. Con respecto a su polémica con Condillac, Bernini advierte con agudeza que se trata, en definitiva, de una colisión de sus respectivas filosofías de la historia: "Lo bárbaro rousseauniano está en ese pensamiento de lo contingente que no puede suscribir el relato progresivo de Condillac. Aun cuando el abad también observa, como Rousseau, que en la historia (...) la unidad original de la música y del lenguaje se pierde, que, consecuentemente, el habla y la canción se separan, que 'la prosodia' empieza 'a retirarse insensiblemente de la música' (...), ese crecimiento de la abstracción y de la lógica en el lenguaje occidental nunca constituye, para Condillac, otra cosa que un progreso hacia el perfeccionamiento de la civilización. En cambio, en Rousseau, la misma transformación histórica de la unidad originaria está vista como un desastre vinculado a la formación de la sociedad, a la salida del estadio frágil y feliz de la barbarie" (Bernini, Emilio, "Introducción", en Rousseau, JeanJacques, Ensayo sobre el origen de las lenguas, Buenos Aires, Colihue, 2015, p. XXXVI). 
(" eloquence muette ») se revela mucho más persuasiva que los largos y elaborados discursos. ${ }^{38}$ Este lenguaje original es necesariamente poético y se expresa mediante tropos; a medida que "las luces se extienden" (" les lumières s'eténdent»), sin embargo, sus características se modifican:

Deviene más justa y menos apasionada; sustituye a los sentimientos por ideas, no le habla más al corazón sino a la razón. El acento se extingue, la articulación se extiende, la lengua deviene más exacta, más clara, pero también más cansina, más sorda y más fría. Ese progreso me parece de todos modos natural ${ }^{39}$.

${ }^{38}$ La defensa rousseauniana de una retórica capaz de despojarse de ornamentos lingǘsticos y que, por el contrario, recupere como insumo central la potencia del gesto tiene continuidad con una tradición muy propia de los siglos XVII y XVIII, que revaloriza la actio por sobre el sermo. Pueden consultarse, al respecto, los trabajos de Goodden, Angelica, Actio and persuasion, Oxford, Clarendon Press, 1986, y de Lichtenstein, Jacqueline, The eloquence of color. Rhetoric and painting in the French classical age, Berkeley-Los Angeles-Oxford, University of California Press, 1993. En este último texto, la autora afirma: "Neither the demonstrative proofs of probare nor the persuassive beauty of delectare (...) would suffice to break down the ultimate and often vague resistances born of love and hate, desire and disgust, compassion and repulsion (...). To sway their listeners, the orator must disturb them with his voice, overwhelm them with his expressions, transport them with his gestures. Delivery must transform the oration into a spectacle, the orator into an actor and the audience into supporters". El objetivo, a partir de entonces, es movere, un sentimiento que supera la distinción entre lo que place y lo que displace y que transporta a la audiencia más allá de su capacidad racional. "The power in this speech, which does not merely please but attempts to inflame, characterizes sublime discours". Sobre la influencia de esta tradición en la teoría dramatúrgica de Diderot, cfr. Olszevicki, Nicolás, op. cit.

39 « Il devient plus juste \& moins passionné ; il substitue aux sentiments les idées, il ne parle plus au cœur, mais à la raison. (...) L'accent s'éteint, l'articulation s'étend, la langue devient plus exacte, plus claire, mais plus traînante, plus sourde \& plus froide. Ce progrès me paroit tout-à-fait natural» (Rousseau, Jean-Jacques, «Essai sur l'origine des langues", Collection complète des Oewvres, Genève, 1780-1789, vol. VIII, p. 370). 
El tránsito final de esta codificación se produce con la emergencia y expansión de la escritura, que despoja al lenguaje de su relación intrínseca con la poesía y con la música. ${ }^{40}$ Así, la fuerza irreproducible de la épica homérica, alojada en la memoria oral de los hombres y no pervertida por la escritura a lo largo de varios siglos, se les manifiesta a los griegos del siglo de oro como un poderoso contraste con sus débiles producciones escritas: "Los otros poetas escribían, sólo Homero cantó, y sus cantos divinos no cesaron de ser escuchados con embeleso sino cuando Europa se cubrió de bárbaros que se dispusieron a juzgar aquello que no podían sentir"41

Tardía intervención en la Querelle des Anciens, el texto de Rousseau denuncia la colonización del sentimiento por parte del juicio racional como una de las causas de la decadencia del gusto por la poesía: de acuerdo con esta provocativa versión, los verdaderos bárbaros no serían ya los hombres primitivos, sensibles por naturaleza, sino los civilizados que no son capaces de sentir visceralmente el efecto que las mejores obras de arte les provocan a quienes pueden librarse a su voluptét2 a la hora de mensurar el valor estético de una pieza.

40 Relación que ya había sido destacada por Condillac (I, II, 8). En tanto que mediación necesariamente artificial entre el sentimiento natural y su expresión, la palabra articulada no puede ser enunciada por Rousseau sino con una profunda culpabilidad. Según Starobinski, "el lenguaje articulado es una mediación ineficaz que traiciona infaliblemente la pureza de la convicción" y, por tanto, Rousseau deberá excursarse de ello "como una falta": "Estaba hecho para el civismo oscuro, para la virtud silenciosa y para el sentimiento que encuentra su placer en sí mismo. Escribir ha sido una caída fatal (por culpa de los falsos amigos, y, sobre todo, de Diderot) que lo expuso a todos los malentendidos. Como castigo no terminará de disipar mediante la palabra autobiográfica los malentendidos creados por la palabra 'literaria"' (Starobinski, Jean, La transparencia y el obstáculo, Madrid, Taurus, 1983, p. 328).

${ }^{41}$ "Les autres Poètes écrivaient, Homère seul avoit chanté, \& ces chants divins n'ont cessé d'être écoutés avec ravissement que quand l'Europe s'est couverte de barbares, qui se sont mêlés de juger ce qu'ils ne pouvoient sentir » (Rousseau, JeanJacques, op. cit., p. 378).

${ }^{42}$ A partir de una cuidadosa lectura del Émile, entre otros textos rousseaunianos, Gabriela Domecq ha mostrado en un trabajo reciente que la voluptuosidad -esto es, el carácter intrínsecamente erótico del encuentro del sujeto con el objeto estéticofunciona en Rousseau como antídoto contra la perversión contemporánea del 


\subsection{Diderot, el lenguaje inarticulado, el gesto}

Aunque menos evidente que la de Condillac, no es aventurado sugerir que alguna influencia pudo tener sobre las especulaciones de Rousseau $-\mathrm{y}$, en particular, sobre sus tajantes opiniones acerca del carácter anti-artístico de la lengua francesa- la lectura de una temprana obra de Diderot, con quien entonces mantenía aún un vínculo de amistad y mutua admiración intelectual. En efecto, la relación entre lenguaje, poesía, civilización y barbarie es uno de los hilos conductores de la Lettre sur les sourds et les muets, la primera obra sometida por el editor de la Encyclopédie para su juicio por parte de la institución encargada de la censura luego de su detención en Vincennes. Como es bien conocido, el nuevo director de la Librairie, Malesherbes, le concedió una «permission tacite» y la obra comenzó a circular en febrero de 1751, al menos cinco años antes de que Rousseau iniciara la escritura de su Essai.

Concebida como respuesta a las Lettres sur la phrase française comparée avec la phrase latine situadas por Batteux al final del Cours de belles-lettres distribué par exercices (1747-1748), la carta es una intervención polémica en un largo debate sobre el grado de naturalidad o artificialidad que se les podía atribuir a las lenguas francesa y latina, medido en base a la cantidad de "inversiones" que empleaba cada una. Mientras los gramáticos de Port-Royal habían sostenido que el francés era la lengua que respondía de manera más natural, en el ordenamiento de sus palabras, al orden habitual del pensamiento (y que, por tanto, podía legítimamente aspirar a convertirse en la lingua franca para la filosofía y la ciencia), Batteux indicaba que, por el contrario, el orden natural era el que iba de la sensación (expresada por los sustantivos) a la intelección (expresada por los verbos), y se manifestaba con más precisión en la oración latina.

En lugar de tomar partido acríticamente por la postura de Port-Royal o por la de Batteux, Diderot corre en su Lettre el eje de la discusión al cuestionar que el lenguaje articulado tout court, sea cual sea el idioma en que

gusto, consecuencia del omnipresente deseo de distinguirse: "La volupté se définit par l'autonomie du jugement de goût et (...) le voluptueux cherche ce qui plaît, non ce qui distingue. La volupté préserve l'objet du goût et l'autonomie du jugement" (Domecq, Gabriela, «L’ordre du goût chez Rousseau », Astérion [En ligne], núm. 16, 2017, mis en ligne le 07 juin 2017, consulté le 26 décembre 2018, p. 11). 
se profiera, pueda corresponderse adecuadamente con un orden previo de la mente. Según explica el philosophe, el solo acto enunciativo comporta una deformación de la sensación en la cual se origina y de la que pretende dar cuenta: la impresión total percibida por el espíritu en un instante de energía máxima se descompone necesariamente en fragmentos sucesivos en el momento de su expresión verbal.

Una cosa es el estado de nuestra alma, otra cosa el modo en que damos cuenta de él ya sea a nosotros mismos, ya sea a otros; otra cosa, la sensación total e instantánea de ese estado; otra cosa, la atención sucesiva y detallada que nos vemos forzados a prestarle para analizarlo, manifestarlo y hacernos entender (...). El espíritu no va a pasos contados, como sí va la expresión. ${ }^{43}$

Si se examinan atentamente los discursos, advierte el philosophe, se puede comprobar que, en efecto,

El estado del alma, en un instante indivisible, fue representado por una multitud de términos que la precisión del lenguaje exigió, y que distribuirán una impresión total en partes; puesto que esos términos se pronuncian sucesivamente y no se escuchan sino a medida que se pronuncian, somos conducidos a creer que las afecciones del alma a las que representan poseen la misma sucesión. ${ }^{44}$

$\mathrm{Al}$ ir un paso más atrás y reconocer un hiato insalvable entre sensación y expresión, es el carácter presuntamente artificial de las

\footnotetext{
43 «Autre chose est l'état de notre âme ; autre chose, le compte que nous en rendons, soit à nous même, soit aux autres ; autre chose, la sensation totale et instantanée de cet état ; autre chose, l'attention successive et détaillée que nous sommes forcés d'y donner pour l'analyser, la manifester et nous faire entendre (...). L'esprit ne va pas à pas comptés comme l'expression » (Diderot, Denis, Lettre sur les sourds et les muets, A.-T., Vol. I, p. 439).

44 «L'état de l'âme, dans un instant indivisible, fut représenté par une foule de termes que la précision du langage exigea, et qui distribuèrent une impression totale en parties ; et parce que ces termes se prononçaient successivement et ne s'entendaient qu'à mesure qu'ils se prononçaient, on fut porté à croire que les affections de l'âme qu'ils représentaient, avaient la même succession » (Ibid., p.369).
} 
inversiones el que se pone en cuestión: para el philosophe, no son más que la inevitable consecuencia de la naturaleza sucesiva de la formulación verbal articulada. Aunque consideradas ahora como un procedimiento habitual, presente de manera necesaria en todas las lenguas, Diderot establece sin embargo una gradación de acuerdo con la cual la sintaxis francesa resulta mucho menos rica en inversiones que la latina o la griega. Es gracias a esta característica -esto es, a su aparente regularidad y orden- que sirve mejor que las otras al ejercicio filosófico o científico:

Siendo la comunicación del pensamiento el objeto principal del lenguaje, nuestra lengua es de todas las lenguas la más pulida, la más exacta y la más estimable; la que, en una palabra, retuvo la menor cantidad de esas negligencias que yo consideraría de buen grado restos del balbuceo de los primeros tiempos; o, para continuar con el paralelo sin parcialidad, diría que hemos ganado, a fuerza de carecer de inversiones, nitidez, claridad, precisión, cualidades esenciales para el discurso, y que hemos perdido calor, elocuencia y energía. Agregaría de buen grado que la marcha didáctica y reglada a la que nuestra lengua es sometida, la convierte en más apta para las ciencias y que, por los giros y las inversiones que se permiten el griego, el latín, el italiano y el inglés, esas lenguas son más ventajosas para las letras. ${ }^{45}$

Si bien ese importante pasaje termina con una conclusión que parece celebrar al francés por sobre el resto de las lenguas, al menos para un lector ingenuo ("hablad griego, latín, italiano al pueblo, pero hablad francés al sabio" [«parlez grec, latin, italien au peuple ; mais parlez français au sage»]), es evidente que, a diferencia de algunos de sus colegas philosophes, Diderot no

45 «La communication de la pensée étant l'objet principal du langage, notre langue est de toutes les langues la plus châtiée, la plus exacte et la plus estimable; celle, en un mot, qui a retenu le moins de ces négligences que j'appellerais volontiers des restes de la balbutie des premiers âges; où, pour continuer le parallèle sans partialité, je dirais que nous avons gagné, à n'avoir point d'inversions, de la netteté, de la clarté, de la précision, qualités essentielles au discours; et que nous y avons perdu de la chaleur, de l'éloquence et de l'énergie. J'ajouterais volontiers que la marche didactique et réglée à laquelle notre langue est assujettie, la rend plus propre aux sciences ; et que, par les tours et les inversions que le grec, le latin, l'italien, l'anglais se permettent, ces langues sont plus avantageuses pour les lettres » (Ibid., p.371). 
está dispuesto a resignar tan fácilmente la potencia poética del lenguaje para garantizar su claridad conceptual. ${ }^{46}$ No es una mera casualidad, en este sentido, que el resto de la carta, que ocupa casi la mitad de sus páginas totales, se abstenga por completo de postular una defensa de la impronta filosófica de la lengua francesa y se dedique, por el contrario, a proponer modos de preservar en ella el espíritu, tan debilitado, del «embleme poétique». Con este objetivo en mente, el autor reconoce que existen ciertos casos en que es conveniente alterar el orden natural de las palabras (esto es, producir intencionalmente inversiones) para lograr crear en el público un efecto de extrañamiento que despierte su aletargada imaginación. La poesía, en particular, es el tipo de discurso que con más provecho puede recurrir a estas alteraciones; gracias a ellas -y no a pesar de ellas-, el espíritu poético "mueve y vivifica todas las sílabas" («meut et vivifie toutes les syllabes») y logra que las cosas sean "dichas y representadas al mismo tiempo" ("dites et représentées tout à la fois»), de manera tal que "al mismo tiempo que el entendimiento las aprehende, el alma se conmueve, la imaginación las ve y la oreja las escucha" («dans le même temps que l'entendement les saisit, l'âme en est émue, l'imagination les voit et l'oreille les entend»). En esos casos, el discurso no es una mera concatenación lógica de términos enérgicos capaces de expresar el pensamiento con fuerza y nobleza sino un "tejido de jeroglíficos" («tissu d'hieroglyphes») que expone ese pensamiento como una pintura, en un momento único. De ahí que, para Diderot, toda verdadera poesía sea "emblemática" («emblématique») 47 .

Así, en lugar de constituir el signo visible del alejamiento de una lengua del orden natural de las sensaciones, las inversiones son consideradas como una herramienta a disposición del poeta que busca reproducir lingüísticamente aquello que, en la mente, no tiene más duración que la del instante. En este sentido, según ha apuntado con agudeza Stéphane Lojkine:

\footnotetext{
${ }^{46}$ Rousseau ya había criticado el carácter seco de la lengua francesa en su Lettre sur la musique Françoise. También Voltaire, en su temprano Essay upon epick poetry, había reconocido la desventaja del francés para la creación poética, aunque no lo atribuía tanto a un defecto de la lengua como a un particular estado del gusto público influenciado por el «esprit géométrique».

${ }^{47}$ Diderot, Denis, Lettre sur les sourds et les muets, A.-T., Vol. I, p. 374.
} 
Cuando el orden de las palabras elegido por el escritor de genio parece aberrante, invertido dirían los gramáticos, es para obligar al oyente a un esfuerzo de memoria y de re-inversión que desencadenará en él el efecto de reencuentro, de concomitancia de las ideas, es decir, el movimiento natural del pensamiento. El orden invertido de las palabras restituye el encuentro natural de las ideas. Es la inversión la que es natural. ${ }^{48}$

La carta termina, de hecho, con un llamamiento explícito a preservar la poesía. Aunque evidentemente más adecuado para las "cosas útiles" («choses utiles»), el francés puede también prestarse para las "cosas agradables" («choses agréables»), como testimonian los ejemplos de Rabelais, Boileau, Corneille, Racine y Voltaire, entre otros. Para lograrlo, es preciso escapar del rigor paralizante del orden, que es justamente lo que intenta con su método ensayístico, anárquico, el homme de génie: "Cualquiera que sea la lengua [en la que escribe], la obra que el genio sostiene no cae jamás” («En quelque langue que ce soit, l'ouvrage que le génie soutient ne tombe jamais»).

Ahora bien: si, como hemos visto, el empleo de las inversiones como herramienta poética no es más que un consuelo frente a la desventaja que las lenguas modernas en general, y el francés en particular, tienen a la hora de transmitir emociones, ¿existe alguna manera más efectiva de reproducir la poderosa energía poética del momento climácico de la sensación? Una posible respuesta a este interrogante puede encontrarse en la primera parte de la carta, que es, según consideramos, la más importante desde el punto de vista de una historia de las ideas estéticas. Diderot esboza allí, en consonancia con los autores del siglo que hemos revisado, una teoría sobre el origen de las lenguas: de acuerdo con su hipótesis sensacionista, las primeras palabras en aparecer fueron los adjetivos, reflejo de las impresiones

48 "Quand l'ordre des mots choisi par l'écrivain de génie paraît aberrant, inversé diraient les grammairiens, c'est pour obliger l'auditeur à un effort de mémoire et de renversement qui déclenchera en lui l'effet de rencontre, de concomitance des idées, c'est-à-dire précisément le mouvement naturel de la pensée. L'ordre inversé des mots restitue la rencontre naturelle des idées. C'est l'inversion qui est naturelle » (Lojkine, Stéphane, «Aux origines de la pensée : le silence, le cri, l'image (la Lettre sur les sourds) », en " Diderot, une pensée par l'image », cours donné à l'université de Toulouse-Le Mirail, année 2006-2007 http://utpictura18.univmontp3.fr/Diderot/DiderotLettreSourds.php). 
sensibles, y recién después los sustantivos y los verbos; mientras en el ámbito filosófico el atributo es considerado habitualmente como una derivación (tanto lógica como cronológica) de la sustancia, en el «orden natural de las ideas» es anterior a ella.

Ahora bien: antes incluso de que existiera la posibilidad de producir sonidos articulados $-\mathrm{y}$, por ende, de que aparecieran las inversiones como rasgos característicos de todas las lenguas-, los hombres se comunicaban mediante el lenguaje gestual, al que Diderot considera, como lo había hecho Condillac con el lenguaje de acción, el modo más natural de dar cuenta de los sentimientos. Es en este contexto que el autor realiza su contundente defensa de la energía expresiva del gesto, ejemplificada por el famoso momento en que Lady Macbeth se lava las manos luego del asesinato de Duncan en la famosa obra de Shakespeare. Diderot advierte, provocativamente, que ese "sublime de situación" ("sublime de situation») es inalcanzable mediante la utilización del lenguaje articulado, puesto que su potencia radica, justamente, en la insignificante $-\mathrm{o}$ nula- mediatización que hay allí entre el sentimiento y su expresión. Esta idea, se sabe, es uno de los ejes organizadores de sus teorías dramatúrgica y pictórica. Los ejemplos pueden multiplicarse ad nauseam, pero baste con señalar, por mor de la brevedad, aunque sea uno. En el Discours sur la poésie dramatique, por caso, el autor se pregunta cuándo es que la naturaleza le ofrece modelos al arte y responde:

Es en los tiempos en que los niños se arrancan los cabellos alrededor del lecho de un padre moribundo, donde una madre descubre su seno y conjura a su hijo por las mamas que lo alimentaron; donde un amigo se corta la cabellera y la esparce sobre el cadáver de su amigo (...). No digo que esas costumbres sean buenas, sino que son poéticas. ${ }^{49}$

La vecindad de los gestos con las sensaciones que los originan y, por consiguiente, su efectividad para evocar enérgicamente esas sensaciones

49 "C'est au temps où les enfants s'arrachent les cheveux autour du lit d'un père moribond, où une mère découvre son sein, et conjure son fils par les mamelles qui l'ont allaité ; où un ami se coupe la chevelure et la répand sur le cadavre de son ami (...). Je ne dis pas que ces moeurs sont bonnes, mais qu'elles sont poétiques ». (Diderot, Denis, Discours sur la poésie dramatique, A.-T., Vol. VII, p. 370). 
originarias en quienes los observan, los convierte para el artista en un insumo imprescindible, acaso tanto o más importante que la lengua misma. Esto explica la estatura ejemplar que adquiere para el philosophe la figura del Filoctetes sofócleo, personaje cuyo sufrimiento se manifiesta apenas en balbuceos y gritos inarticulados y que, por eso, puede funcionar como disparador privilegiado de la recepción empática y comprometida que persigue la renovadora teoría teatral de la segunda mitad del siglo. La extraordinaria conmoción que genera Filoctetes en el público no se produce a pesar de su incapacidad de dominar la lengua de la filosofía (o la lengua articulada tout court) sino gracias a ella: el gesto triunfa sobre el discurso.

En las Conversations sur le fils naturel, nuevamente los gritos del personaje sofócleo en la entrada de su caverna son citados como ejemplo de un lenguaje inarticulado que conmueve más que el erudito verso francés:

¡La verdad! ¡La naturaleza! ¡Los Antiguos! ¡Sófocles! ¡Filoctetes! El poeta lo mostró en la escena, acostado a la entrada de su caverna y cubierto de harapos desgarrados. Rueda por el piso, manifiesta un ataque de dolor, grita, hace oír voces inarticuladas. La decoración era salvaje; la pieza se conducía sin tantos aparatos. Hábitos naturales, discursos naturales, una intriga simple y natural. Nuestro gusto estaría muy degradado si ese espectáculo no nos conmoviera más que el de un hombre ricamente vestido, apretado entre sus adornos. ${ }^{50}$

En la tardía Paradoxe sur le comédien, es nuevamente Filoctetes quien opera como personaje prototípico para el nuevo tipo de tragedia que quiere establecer Diderot. Gracias a escenas en las que no se matizaba el pathos, sino que se lo exhibía con toda su fuerza -escenas que las codificaciones académicas, especialmente luego de la Querelle du Cid, habían concluido por dejar fuera del escenario francés- Esquilo, Sófocles y Eurípides, entre otros,

\footnotetext{
50 «La Vérité ! la Nature ! Les Anciens ! Sophocle! Philoctète ! Le poète l'a montré sur la scène, couché à l'entrée de sa caverne, et couvert de lambeaux déchirés. Il s'y roule ; il y éprouve une attaque de douleur ; il y crie ; il y fait entendre des voix inarticulées. La décoration était sauvage ; la pièce marchait sans appareil. Des habits vrais, des discours vrais, une intrigue simple et naturelle. Notre goût serait bien dégradé, si ce spectacle ne nous affectait pas davantage que celui d'un homme richement vêtu, apprêté dans sa parure »(Diderot, Denis, Conversations sur Le fils naturel, A.-T., Vol. VII, pp. 120-121).
} 
habían logrado "no solo entretener a sus co-ciudadanos, sino tornarlos mejores" («non pas amuser seulement leurs concitoyens, mais les rendre meilleurs»). Para ello, en lugar de imponer restricciones convencionales, los tempranos poetas habían optado por valerse del lenguaje de la cotidianeidad. A pesar de su extensión, conviene reproducir un importante fragmento de ese diálogo:

El primero: Es verdad que me siento encantado de escuchar a Filoctetes diciéndole tan simple y fuertemente a Neptolemo, cuando le devuelves las flechas de Hércules que había robado a instigación de Ulises: "Mira qué acción cometiste: sin darte cuenta, condenas a un malherido a perecer de dolor y de hambre. Tu robo es el crimen de otro, tu arrepentimiento depende de ti. No, jamás habrías pensado en cometer semejante indignidad si hubieras estado solo. Comprende entonces, hijo mío, cuanto importa a tu edad frecuentar solamente personas honestas. He aquí lo que tenías para ganar con la sociedad de un miserable. ¿Y por qué asociarte a un hombre con ese carácter? ¿Es quien tu padre hubiese elegido por compañía y por amigo? Ese digno padre que no dejaba aproximarse sino a los personajes más distinguidos del ejército, ¿qué te diría, si te viera con un Ulises?”. ¿Hay algo en ese discurso que no podría decirle yo a su hijo, y usted al mío?

El segundo: No.

El primero: Y sin embargo es bello.

El segundo: Sin dudas.

El primero: $\mathrm{Y}$ el tono de ese discurso pronunciado sobre el escenario, ¿diferiría del tono con el que se pronunciaría en sociedad?

E1 segundo: No lo creo.

El primero: $\mathrm{Y}$ ese tono en la sociedad, ¿sería ridículo?

E1 segundo: De ninguna manera.

El primero: Cuanto más fuertes son las acciones y más simples los propósitos, más los admiro. Temo que hayamos tomado durante cien años seguidos las fanfarronadas de Madrid por el heroísmo de Roma y 
que hayamos enturbiado el tono de la musa trágica con el lenguaje de la musa épica. ${ }^{51}$

Si bien en este intercambio no se destaca particularmente la importancia del gesto, es nuevamente la deseable cercanía del lenguaje artístico (en este caso, teatral) con el lenguaje natural, cotidiano, la que emerge como garantía de belleza. Llevado ese razonamiento al límite, se podría postular que, de acuerdo con la estética naturalista diderotiana, el verdadero poeta no podría desarrollarse nunca en los períodos luminosos de la civilización, en los que el lenguaje necesariamente se refina y se complejiza, sino que sería siempre, en esos contextos, un evento del pasado: habría emergido únicamente en los balbuceantes tiempos iniciales de la humanidad para perderse de una vez y para siempre en los laberintos geométricos de la racionalidad ilustrada. La gran poesía, que como se recordará necesita, para Diderot, “cierta dosis de lo enorme, de lo salvaje, de

51 «Le premier : Il est vrai que je suis enchanté d'entendre Philoctète dire si simplement et si fortement à Néoptolème, qui lui rend les flèches d'Hercule qu'il lui avait volées à l'instigation d'Ulysse : «Vois quelle action tu avais commise : sans t'en apercevoir, tu condamnais un malheureux à périr de douleur et de faim. Ton vol est le crime d'un autre, ton repentir est à toi. Non, jamais tu n'aurais pensé à commettre une pareille indignité si tu avais été seul. Conçois donc, mon enfant, combien il importe à ton âge de ne fréquenter que d'honnêtes gens. Voilà ce que tu avais à gagner dans la société d'un scélérat. Et pourquoi t'associer aussi à un homme de ce caractère ? Était-ce là celui que ton père aurait choisi pour son compagnon et pour son ami ? Ce digne père qui ne se laissa jamais approcher que des plus distingués personnages de l'armée, que te dirait-il, s'il te voyait avec un Ulysse ? ... » Y a-t-il dans ce discours autre chose que ce que vous adresseriez à mon fils, que ce que je dirais au vôtre ?/ Le second: Non/ Le premier: Cependant cela est beau/Le second: Assurément/Le premier: Et le ton de ce discours prononcé sur la scène différerait-il du ton dont on le prononcerait dans la société ?/Le second: Je ne le crois pas/Le premier: Et ce ton dans la société, y serait-il ridicule ?/Le second: Nullement/ Le premier: Plus les actions sont fortes et les propos simples, plus j'admire. Je crains bien que nous n'ayons pris cent ans de suite la rodomontade de Madrid pour l'héroïsme de Rome, et brouillé le ton de la muse tragique avec le langage de la muse épique » (Diderot, Denis, « Paradoxe sur le Comédien », A.-T., vol. VIII, p. 406). 
lo bárbaro", devendría imposible bajo el reinado frío de la filosofía. Tal idea aparece, de hecho, bellamente recuperada en sus Réflexions sur Térence:

Un caníbal enamorado que se dirige a una culebra y le dice: " $¡ C u l e b r a$, detente, culebra! A fin de que mi hermana pueda extraer del patrón de tu cuerpo y de tu piel la hechura y la obra de un bello cordón que pueda regalarle a mi amada; de modo que tu forma y tu belleza sean, en todos los tiempos, preferidas a las de todas las otras serpientes". Ese caníbal tiene elocuencia, también tiene gusto. ${ }^{52}$

La primitiva lengua de ese hipotético hombre natural, que ni siquiera tiene por interlocutor a otro ser humano, adquiere, provocativamente, un carácter ejemplar: libre de toda convención arbitraria, ajena a los prejuicios sociales, la palabra del caníbal enamorado se convierte en la más acabada síntesis del genio y del gusto.

\section{Bibliografía}

- Aarsleff, Hans, "Philosophy of language", en Haakonsen, Knut (coord.), Cambridge History of Eighteenth Century Philosophy, Cambridge, Cambridge UP, 2006, pp. 451-496. - Adamovsky, Ezequiel, Euro-Orientalism: The Image of Russia in France, c. 1740-1880, Oxford, Peter Lang, 2006.

- Baker, Eric, "Lucretius in the European Enlightenment", en Gillespie, Stuart, The Cambridge Companion to Lucretius, Cambridge, Cambridge University Press, pp. 274288.

- Bernini, Emilio, "Introducción”, en Rousseau, Jean-Jacques, Ensayo sobre el origen de las lenguas, Buenos Aires, Colihue, 2015.

- Batteux, Charles, Les Beaux-Arts réduits à un même principe, Paris, Durand, 1746.

- Boletsi, Maria, Barbarism and its discontents, California, Stanford University Press, 2016.

52 «Un Cannibale amoureux qui s’adresse à la couleuvre et qui lui dit : 'Couleuvre, arrête-toi, couleuvre! Afin que ma sœur tire sur le patron de ton corps et de ta peau la façon et l'ouvrage d'un riche cordon que je puisse donner à ma mie ; ainsi soient, en tout temps, ta forme et ta beauté préférées à tous les autres serpents'; ce Cannibale a de la verve, il a même du goût ». (Diderot, Denis, "Éloge de Terence", A.-T., Vol. V, p. 233). 
- Burello, Marcelo, Autonomía del arte y autonomía estética. Una genealogía, Buenos Aires, Miño y Dávila, 2015.

- Condillac, Étienne Bonnot de, Essai sur l'origine des connaissances bumaines, Paris, Mortier, 1746.

- Delon, Michel, «La beauté du crime », Europe, núm. 661, 1984, pp. 73-83.

- Delvaille, Jules, Essai sur l'bistoire de l'idée de progrès jusqu'à la fin du XVIII siècle, Paris, Alcan. 1910.

- Diderot, Denis, Euvres complètes, texte établi par J. Assézat et M. Tourneux, Paris, Garnier, vingt volumes, 1875-1877.

- Domecq, Gabriela, "L'ordre du goût chez Rousseau », Astérion [En ligne], núm. 16, 2017, mis en ligne le 07 juin 2017, consulté le 26 décembre 2018

- Du Bos, Jean-Baptiste, Réflexions critiques sur la poésie et la peinture, Paris, Pissot, 1755.

- Faguet, Émile, Dix-buitième siècle : études littéraires, Paris, Société française d'imprimerie et de librairie, 1898.

- Ginzo, Arsenio, "Las aporías de la utopía. Progreso y primitivismo en Diderot", Anales del seminario de Historia de la Filosofía, núm. 14, 1997, pp. 43-71.

- Goggi, Gianluca, "Diderot et le concept de civilisation", Dix-buitième siècle, núm. 29, 1997, pp. 353-373.

- Goodden, Angelica, Actio and persuasion, Oxford, Clarendon Press, 1986.

- Hartog, François, Memoria de Ulises, Buenos Aires, FCE, 1999.

- Hundert, Edward J., "The Thread of Language and the Web of Dominion: Mandeville to Rousseau and Back", Eighteenth-Century Studies, Vol. 21, núm. 2, 1987, pp. 169-191.

- Krakeur, Lester, "Diderot and the Idea of Progress", Romantic Review, núm. 29, 1938, pp. 151-159.

- Lacoue-Labarthe, Philippe, Typography. Mimesis, Philosophy, Politics, Cambridge, Harvard University Press, 1989.

- Levine Gera, Deborah, Ancient greek ideas on speech, language and civilization, Oxford, Oxford UP, 2003.

- Lichtenstein, Jacqueline, The eloquence of color. Rhetoric and painting in the French classical age, Berkeley-Los Angeles-Oxford, University of California Press, 1993.

- Lojkine, Stéphane, «Aux origines de la pensée : le silence, le cri, l’image (la Lettre sur les sourds) ", en " Diderot, une pensée par l'image », cours donné à l'université de Toulouse-Le Mirail, année 2006-2007 http://utpictura18.univmontp3.fr/Diderot/DiderotLettreSourds.php).

- Lotterie, Florence, Progrès et perfectibilité : un dilemme des Lumières françaises (17551814), Oxford, Voltaire Foundation, 2006.

- Mortier, Roland, Clartés et ombres du Siècle des Lumières, Genève, Droz, 1969.

- Muthu, Sankar, Enlightenment against empire, Princeton, Princeton University Press, 2003 
- Olszevicki, Nicolás, "L'ekphrasis dans la théorie dramatique de Diderot», Recherches sur Diderot et sur l'Encyclopédie, 2016/1, núm. 51, pp. 63-73.

- Ratto, Adrián, "Naturaleza e historia en la obra de Denis Diderot", Revista de Filosofía y Teoría Política, núm. 41, 2010. pp. 129-153.

- Ratto, Adrián, "El pesimismo histórico en la filosofía de Denis Diderot", Tópicos. Revista de Filosofía de Santa Fe, núm. 22, 2011, pp. 211-231.

- Ricken, Ulrich, «Réflexions du XVIIIe siècle sur l'abus des mots », Mots, núm. 4, 1982, pp. 29-45.

- Rosenfeld, S., A Revolution in Language. The Problem of Signs in Late Eighteenth-Century France, Stanford, Stanford University Press, 2001.

- Rousseau, Jean-Jacques, Collection complète des Oeuvres, Genève, éditeur non identifié, 17 vols., 1782-1789.

- Stanley, Sharon, "Unravelling Natural Utopia. Diderot's Supplement to the Voyage de Bougainville”, Political Theory, Vol. 37, núm. 2, 2009, pp. 266-289.

- Starobinski, Jean, La transparencia y el obstáculo, Madrid, Taurus, 1983.

- Steintrager, James, Cruel Delight: Enlightenment Culture and the Inbuman, Bloomington, Indiana University Press, 2004.

Recibido: 06/19. Aceptado: 10/19 